\title{
Complexity and Design for Wellbeing in Community Participation
}

\author{
Karen George, Petia Sice, Safwat Mansi, Jeremy Ellman \\ Computer, Engineering \& Information Science \\ Northumbria University \\ Newcastle upon Tyne, UK
}

\author{
Robert Young \\ School of Design \\ Northumbria University \\ Newcastle upon Tyne, UK
}

\begin{abstract}
The UK Government calls for more effective ways of communicating and engaging with the community to devolve power and enable local improvements in the concept of the 'Big Society'. Devolved power is often gained through local community associations. Their wellbeing is a prime focus as they often struggle for capable volunteers as they compete with the well known giants of the voluntary sector who have significant marketing budgets. Community associations need to develop their use of information technology so they can compete for sustainability, particularly when competing for volunteers. When a member of the community decides to participate there are a series of local social interactions that take place, culminating in a tipping point. This is a complex area with many different sources of information linking into community participation. There is prior evidence of complex networks with active communicating social agents, which show emergent properties. Exploitation of these local interaction and emergent properties for enhanced community participation will have a powerful influence. The aim of this research is to develop a frame of reference for effective community participation through ICT, applying both complexity and design perspectives to recognize the role of local interactions. The research starts by constructing a narrative of experiences to help develop semistructured interviews. This information will then be used in workshops to look at how the results can be effectively communicated to the public and encourage virile tipping points The successful outcome will be an effective and efficient, time saving framework.
\end{abstract}

Keywords - Community Participation, ICT, Complexity and Design Theory, Big Society, Third and Community Sector.

\section{Introduction}

Each UK Local Authority has been tasked with reviewing their community assets, as a major part of the budget review. Communities are being tasked to take on board the role of asset management of the community buildings. This calls for a new breed of community participant with appropriate skills to take on property management as well as service development. Community associations are currently under tremendous stress and this additional pressure may have a detrimental impact on their wellbeing.

The 'New Philanthropy Capital' states the importance of community associations and agrees that their community participants are stressed and lack the skills needed for best practice [1]. This limits what they can do and the funds they can apply for. The lack of skills also adds stress to any paid staff as there is an absence of professional guidance. They suggest filling the skills gap with people from outside the local community. It is not easy to gain interest from people outside of the local community with no prior knowledge of the organisation.

Community associations need to develop their use of information technology so they can compete with the voluntary and private sectors for sustainability, particularly when it comes to competing for volunteers. The 'Communities in control: real people, real power.' report raises the need for the Government to find more effective ways of communicating and engaging with the community and devolving power to enable improvements [2]. To develop IT skills the community sector needs more volunteers in place to support this process. There needs to be intrinsic research into how ICT can maximise community participation. This requires collaborative working between local government, private and the community sector to ensure adequate local social interactions take place. If the interactions are well connected they will have a powerful influence at a global level [3]. These interactions are part of complex networks which emerge into tipping points. Online communication mediation can play a significant role in facilitating the phenomenon of these tipping points for community participation [4].

A Third Sector Excellence program was instigated by the Government to support the research development and deployment for the management of information, knowledge and best practice within the community sector. In support of best practice the Social Impact of ICT report was requested through the University of Siegen by the European Commission [5]. The European Commission, National and Local Government are asking members of the community to engage more in community 
participation and to make better use of ICT. There is a need for research into more than just using ICT but embracing it so that it enhances the wellbeing of community associations by deciphering what information really needs to be marketed and how it should be communicated to maximise effective participation.

Present community participation systems tend to be quite crude and make assumptions with regards to the minimal information gathered. The reason given for this is to make it easy for the member of the community to complete.

We need to change the way we think about community participation and how we support the expanded use. Community associations are just as unique as people, both are complex. To ensure the best fit the relevant information needs to be gained from each to create a beneficial partnership.

\section{Current Research in Community Participation with ICT}

The main focus for community participation research is currently based on studies regarding communication and information sharing between the government and the public for political gain and government business. This research has generally monitored practice to gain insight and is largely based on observations of how members of the community engage with technology and follow up interviews with participants attending ICT workshops [6]. There is some research focused on leadership and management of virtual community groups [7]. These studies are also based on analysing observed practice and interviews. The Walters and Williams [8] research analysed actual tweets to establish if the information was mainly one or two way communication. Their results showed the majority of information was only one way as government tends to redirect questions to other sites showing a lack of communication.

Absent in the studies outlined above is the directing attention to how online communication can benefit community participation as it emerges through local interactions, such as:

- Regular volunteering for a non-electoral organisation

- Active membership in a group or association

- Participation in fund-raising e.g. running/walking/cycling

- $\quad$ Other fund-raising for charitable purposes

- Community problem solving

- Asset management of community buildings

- $\quad$ Service development

- Human resource management

- Financial management, etc.
It is important to focus on understanding the dimensions and quality of interactions within community participation. In particular those interactions that make members of the community initially decide to participate. What are the critical tipping points that motivate people to participate and what can be designed to exploit this through the use of ICT? A tipping point is a critical moment in a series of events when unprecedented changes occur quite rapidly with irreversible effect. The concept of 'tipping points thinking' connected with insights from complexity theory suggests that in well connected networks minor changes can lead to significant change. Ideas, behaviour, messages and even products sometimes behave just like outbreaks of infectious disease. Hence the popular term 'gone viral'. The tipping point in this research is an examination of the social epidemics that effect community participation [9]. These social epidemics could be innovatively exploited to enhance community participation.

\section{Rationale for complexity and design approach}

\subsection{Complexity theory}

The day to day dynamics of life are complex with an array of knitted characteristics forming local social interactions. The local social interactions emerge in turn into processes. These processes formulate activities known as social systems and or day to day phenomena. The social systems have a knock on effect causing more local social interactions and emergent processes. This research will look at the local social interactions and emotions of community participants. Human thinking, level of understanding, feeling, energy, relationships, influence, the environment and timing from chaos, flow together to create local social interactions, which form patterns, sometimes unique patterns. These patterns change depending upon the ratings and or amount of each of the ingredients. Just like cooking an egg it depends on how you cook it and what you add as to whether you get an omelette, scrambled, poached, boiled, fried, hard, soft, over or under cooked egg for your meal. In the dynamics of community participation the ingredients come from that same bottom up approach although there are many more characteristics so it is much more complex. There are two major complex strands to community participation with individual members of the community and community associations. You could go further than this as legislation and government influence how each can behave. However assumptions should not be made and too many restrictions limit the creativity of volunteers. The challenge of a dysfunctional community 
association could be appealing to a member of the community, e.g., they may have a boring life, feel so frustrated, may give them the experience they need to challenge the same issue at work or home. Complexity theory offers an approach which represents the learning and innovation dynamics of social systems as an emergent rather than a managed process and offers tools for dynamic analysis of systems behaviour [10]. However, rigorous models are yet to be developed as the impact of the insights of complexity theory into human affairs and the use and role of ICT and Web technologies have not been fully appreciated [11]. Communities are social systems where people make a commitment to be there for each other and they participate not only for their own needs but for the need of others. Thus, it is important to consider communities as an emergent phenomenon and take a more generative perspective in terms of seeking to understand how communities function from within. It is equally important to consider what makes people contribute to each other and be there for each other in an area of common interest.

\subsection{Design Theory}

Design appears to take complexity and all it's fuzziness as a challenge, embracing it. Design also needs to have established the array of knitted characteristics with their cause and effect. If we consider the aspect of emergence of new forms of action serving the community and or its environment we are entering the discourse of design [12]. Design theory focuses on the interactions and processes that enable individuals and communities to engage in the creation of new activities or infrastructures [13]. Design in this instance focuses on the value of local social interactions to the community participants, the process, employees and management committee members in community associations, knowledge management and society. It also investigates the effects of the environment. It considers innovation to clarify complexity, scoping the objects, services and processes to collaboratively formulate a new way forward. Design studies suggest that information and communication technologies can contribute to emergent social innovation [14]. Social innovation fits well with the third sector as it promotes involvement, empowerment and ownership. These will act as motivators for the acceptance of the research and new developed practices.

Design can challenge the present simplistic IT systems to provide a service that is unique to the individual and enhance their experience. Communication needs to be relevant to community members. There are innovative ways of making people part with information without it being cumbersome. Using existing community participants to design through social innovation appropriate and fun ways of gaining this complex and unique information will encourage engagement and support enhanced participation. This way no assumptions are made, the participants are experienced volunteers so they fully understand the field of research. They will fully understand the interrelationships and their emergence into social interactions giving them a deep understanding of meaning.

\subsection{Synergies}

This research proposes to explore synergies between design and complexity thinking to develop understanding of the motivational factors in community participation and online communication mediation. In particular it is looking at the value of the information communicated and how this promotes wellbeing. Designing from complexity is about developing technology for a supporting role in a people centred world [15]. Complexity and design theory favour the use of narratives with clients in the field of study. A method which is favoured by the third sector as it leads to more ownership to the outcome. To simplify, complexity theory can be used to make sense of community participation tipping points (human behaviour). Design theory can utilise established complex data to design a complex system of solution focused IT interactions. The two theories work in partnership to investigate and develop frameworks for human performance technology. Complexity and design theory can embrace life phenomena to communicate and control in life like emergent patterns.

\section{Research}

\subsection{Research Question}

The research will address this question:

"What are the motivational tipping points in community participation and how can they be utilised to maximise active engagement through ICT?”

\subsection{Research Aim}

The aim of this research is to develop a framework for conceptualising an online communication mediation system for effective community participation applying both complexity and design perspectives. This links to both the current UK 'Empowering Local Communities' policy agenda and to practical ways of developing community participation; in keeping with the aspirations of the Big Society [16]. 


\subsection{Research Objectives}

The research is not just about enhancing communication with regards to community participation, it looks at what essentially needs to be communicated and how that information can be utilised through ICT to create an effective way to maximise participation. The research looks at the community sector as it is the area in most need within community participation. The framework designed will be promoted within a new website for community associations to support their excellent work.

The research objectives are to:

- Evaluate the application of complexity and design insights into effective community participation;

- Apply this to develop an approach to the study of community participation;

- Utilise the approach and conduct research with the participating north east community organisations to identify the motivational factors of community participation;

- Design and evaluate a framework and guidelines for beneficiaries for conceptualisation of an online communication mediation system for effective community participation

These objectives will only be successful with necessary ingredient which is people who are actively involved in the community sector.

\section{The Indicative Methodology}

The methodology for the proposed research will include action research and reflective practice, as the researcher will be involved in the study and development of community participation with the participating organisations and members of the community.

Action research approach is based on improvement of a practice; the improvement of the understanding of a practice by practitioners and the improvements of situation in which the practice takes place [17]. This fits with best practice which is an area being promoted in the community sector. It involves the members of the community which enhances ownership.

Action research in a natural environment allows the researcher to not only play the role of investigator but also a collaborator, a facilitator along with a participatory character; commitment and personal involvement in the research activity is emphasised [18]. The researcher will act as a reflective practitioner as both reflective (reflection on practice) and reflexive practice will be required [19]. Reflexive practice demands awareness that the researcher is an individual with a particular social identity, background and culture that may have an impact on the research process, a participant observation [20]. Reflexivity can be used to identify areas of potential researcher's bias. Through interpretivism the data will be used to ascribe and understand the significance of participants' constructed reality and their subjective views of the tipping point.

This research process will include narrative data collection from the umbrella organisations to find out what their needs are and to gain reflective and reflexive views on effective community participation. The participants will sign a contract at the beginning of the narrative agreeing to only narrate truthful first hand experiences so as to ensure the quality of the narratives. The researcher has 30 years experience in the field so will be able to ask questions if anything out of the ordinary is narrated. The other members of the group will also be able to ask for clarification or give supportive agreement from their own experiences. These findings will be evaluated to rank a list of community participation characteristics and prioritise in their view what are the motivational factors. These results will be clarified with the umbrella organisations as an additional verification.

This information will direct the themes for the semi-structured interviews which will be used to gather participation characteristics from the actual community participants. They will be asked to rate certain feelings, emotions, needs, etc against good and bad experiences. This will help develop an understanding of the quality of interactions and critical tipping points that are needed for effective community participation. The evaluation of this will lead to the production of a draft framework

The workshops should allow for reflection on the draft framework. More specifically how the tipping points effect community participation. This will be discussed in the workshops whereby the participants will be asked to socially innovate how ICT could play an improved role in effective community participation. What would satisfy their wellbeing for effective involvement? Participants will be encouraged to act out, artistically promote, narrate, etc., motivational factors from which promotional material will be designed which could be used for effective online communication mediation.

The correlations from the narratives and semi structured interviews will be compared with information from the workshops which should help develop a comparative list of revised motivational factors versus community participation characteristics. These will be interpreted to design the final proposition framework. This will be fed 
back to the participants for peer review. This review will guide the development of a full list of beneficiaries to promote the wellbeing community participation framework for ICT.

\section{Field of research}

The study will be within the North East mainly focusing in Durham and Newcastle. The following organisations will be involved: Northumberland Clubs for Young People - a youth support and development agency; Mind Tyneside - helps people take control of their Mental Health; Newcastle Community Buildings Network - Supports Community Associations in Newcastle; Ouseburn Trust - a development trust; Durham County Council - Community and Youth Development section and Newcastle City Council - Community Engagement section.

\section{Conclusion}

The wellbeing of community participants is a motivational factor for the research. Involvement from the public, community and third sectors gives this research credibility with the individuals concerned. Community participation has repeatedly been highlight as an area of need and yet still no real answer has been found. The contribution to knowledge acquired will be the development of a framework for online communication mediation for effective community participation. The community sector will be able to exploit this information for their benefit. There will be a synergy of insight into community participation from the perspectives of complexity and design theories. This will show how they work in partnership in third sector research. The case studies into motivational factors in community participation will be available for others to review.

The impact of the research could be global. However, within the UK the Third Sector and Local Government will benefit with an effective and efficient, time saving model to promote community participation. It will produce a tried and tested approach for community participation. As A4E have the contract for supporting people into work they can benefit from this system for their clients with community participation roles until paid work is established. It can be an ideal way of gaining work experience and expanding your CV. Previously volunteer placements have sometimes been cumbersome for community associations, or boring for community participants, as neither needs have been taken into consideration causing disharmony which can lead to stress. An additional benefit will be the improved collaborative knowledge sharing partnership between Higher Education providers, Local Government and Third Sector organisations.

\section{References}

[1] [20] Hudson, S. (2011) 'Community organisation boards are often short of skills' TSO, Haymarket Business Interactive, London http://www.thirdsector.co.uk/channels/Governance/Article/ 1063067/Community-organisation-boards-often-shortskills/ (13th July 2011).

[2] Communities and Local Government. (2008) 'Communities in control: real people, real power', TSO, Norwich.

http://www.communities.gov.uk/documents/communities/ pdf/886045.pdf (31st Aug 2010).

[3] Wheatly, M. and Frieze, D. (2006) 'Using emergence to take social innovation to scale', http://www.margaretwheatley.com/articles/emergence.htm l (19th March 2011).

[4] Gilchrist, A. (2009) 'The Well-Connected Community: A networking approach to community development', The Policy Press, http://lib.myilibrary.com?ID=250160 (14th June 2011).

[5] University of Siegen (2010)

'Study on the Social Impact of ICT', http://ec.europa.eu/information_society/eeurope/i2010/doc s/eda/social_impact_of_ict_exec_sum.pdf (13th March 2011).

[6] Hill, R., Beynon-Davies, P. and Williams, M. D. (2008) 'Older people and internet engagement: Acknowledging social moderators of internet adoption, access and use', Emerald Group Publishing Limited, Information Technology \& People, Volume 3, Issue 21, pp. 244 - 266.

[7] Vaccaro, A. \& Madsen, P. (2009) 'ICT and an NGO: Difficulties in attempting to be extremely transparent', Springer Science and Business Media, Ethics and Information Technology, Volume 3, Issue 11, pp. 221-231.

[8] Waters, R. D. \& Williams, J. M. (2011) 'Squawking, tweeting, cooing, and hooting: analyzing the communication patterns of government agencies on Twitter', Journal of Public Affairs (early view), DOI: 10.1002/pa.385 (17th March 2011).

[9] Gladwell, M. (2000) The Tipping Point: How Little Things can make a Big Difference, Abacus, London.

[10] Small, A., Sice, P. \& Venus, T. (2008) 'A framework for promoting learning in IS design and implementation', Learning organization,: http://hdl.handle.net/10145/77383 (13th April 2011).

[11] Stacey, R. D. (2010) Complexity and organizational reality: uncertainty and the need to rethink management after the collapse of investment capitalism, 2nd ed. edn., Routledge, London.

[12] Johnson, J., Zamenopoulos, T. \& Alexious, K. (2005) Proceedings of the ECCS 2005 Satellite Workshop: Embracing Complexity in Design Linking design and 
complexity: a review. Paris 17 November 2005, Open University, London.

[13] Schuler, D. \& Namioka, A. (eds.) (1993) Participatory Design Principles and Practices, Lawrence Erlbaum Associates, New Jersey.

[14] Jason, L. et al (2006) Participatory community research: theories and methods in action, 2nd ed. edn,. Washington, DC, American Psychological Association, London.

[15] Thackara, J. (2006) In the Bubble: Designing in a Complex World, MIT Press, London.

[16] Cabinet Office (2011) Big Society - overview, http://www.cabinetoffice.gov.uk/content/big-societyoverview (28th April 2011).

[17] Robson, C. (2002) Real World Research: a Resource for Social Scientists and Practitioner-Researchers, 2nd edn., Blackwell, Oxford.

[18] Sarantakos, S. (2005) Social research, 3rd ed. edn., Palgrave Macmillan, Basingstoke.

[19] Schön, D. A. (1983) The Reflective Practitioner- how professional think in action, Basic Book, Inc., USA.

[20] McKernan, J. (1996) Curriculum action research: a handbook of methods and resources for the reflective practitioner, 2nd ed. edn, Kogan Page, London. 